\title{
The expression and significance of HOX transcript antisense RNA and epithelial-mesenchymal transition-related factors in esophageal squamous cell carcinoma
}

\author{
CHUNLI DA ${ }^{1 *}$, YIYI ZHAN ${ }^{2 *}$, YU LI $^{3}$, YAO TAN $^{1}$, RUIGUANG LI $^{4}$ and RUOZHENG WANG ${ }^{1}$ \\ Departments of ${ }^{1}$ Radiotherapy for Head and Neck, ${ }^{2}$ Chemotherapy for Lung Cancer, ${ }^{3}$ Gerontology, and ${ }^{4}$ Endoscopic \\ Diagnosis and Treatment Center, Tumor Hospital of Xinjiang Medical University, Urumqi, Xinjiang 830000, P.R. China
}

Received December 8, 2015; Accepted December 7, 2016

DOI: $10.3892 / \mathrm{mmr} .2017 .6210$

\begin{abstract}
The present study investigated the correlation and significance of HOX transcript antisense RNA (HOTAIR) and epithelial-mesenchymal transition (EMT)-related factors in the occurrence and metastasis of esophageal squamous cell cancer (ESCC) progression. The mRNA and protein expression levels of HOTAIR and EMT-related factors were detected in 96 ESCC and para-carcinoma tissues using reverse transcription-quantitative polymerase chain reaction and western blot analysis. The expression levels of these factors, and the correlation between these factors and clinicopathological characteristics were subsequently analyzed. HOTAIR mRNA expression levels were significantly higher in ESCC compared with in para-carcinoma tissues, and HOTAIR mRNA expression levels were significantly higher in the groups with lymph node involvement or organ metastasis compared with the group without. Furthermore, HOTAIR expression levels demonstrated a significant increasing trend from well-differentiated cancer to poorly differentiated cancer. The mRNA and protein expression levels of zinc finger protein SNAI1 (Snail) and $\beta$-catenin in ESCC were significantly higher compared with para-carcinoma tissues, whereas E-cadherin mRNA and protein expression levels were lower in ESCC tissues compared with in
\end{abstract}

Correspondence to: Dr Ruozheng Wang, Department of Radiotherapy for Head and Neck, Tumor Hospital of Xinjiang Medical University, 789 Suzhou Road, Urumqi, Xinjiang 830000, P.R. China

E-mail:wrz8526@163.com

Dr Ruiguang Li, Endoscopic Diagnosis and Treatment Center, Tumor Hospital of Xinjiang Medical University, 789 Suzhou Road, Urumqi, Xinjiang 830000, P.R. China

E-mail: ruiguangl@sina.com

*Contributed equally

Key words: ESCC, HOTAIR, EMT, Snail, E-cadherin, $\beta$-catenin para-carcinoma tissues. Snail mRNA and protein expression levels were also significantly higher in groups with lymph node involvement or organ metastasis compared with those without, and $\beta$-catenin protein expression levels were significantly higher in the groups with lymph node involvement or organ metastasis compared with the group without. In the 96 ESCC tissues, HOTAIR mRNA expression levels were positively correlated with Snail mRNA and protein expression levels, and were negatively correlated with E-cadherin expression levels. HOTAIR mRNA expression levels were also positively correlated with $\beta$-catenin mRNA expression levels. In conclusion, HOTAIR may be involved in carcinogenesis and metastasis, and may induce the expression of EMT-related factors; detection of these factors may assist in early diagnosis and prognostic prediction.

\section{Introduction}

Esophageal cancer is a common malignant tumor of the digestive tract, with high morbidity and mortality rates of all cancers in China (1,2). The main pathological types of esophageal cancer are esophageal adenocarcinoma and esophageal squamous cell cancer (ESCC), which accounts for $90 \%$ of esophageal cancer cases in China (3). The development of radical and synchronized radiotherapy and chemotherapy for the treatment of local advanced esophageal cancer has improved the survival rate; however, the rate of local recurrence and distant metastasis remains high (4). Chemo-radiotherapy resistance is considered the most important reason for local tumor recurrence and metastasis (5). Therefore, the identification of clinically applicable biomarkers for early evaluation of ESCC prognosis is important.

Long non-coding RNA (lncRNAs) are non-protein coding RNAs $>200$ nucleotides long, which regulate gene expression epigenetically, transcriptionally and post-transcriptionally. Previous studies have suggested that lncRNAs associated with chromatin-modifying complexes may affect epigenetic information and confer numerous properties required for tumor progression and metastasis (6-8).

HOX transcript antisense RNA (HOTAIR) is one of the few well-documented lncRNAs. It consists of 2,158 bp and is located on chromosome 12 within the homeobox $\mathrm{C}$ 
gene cluster (9). HOTAIR has been demonstrated to be highly expressed in primary and metastatic breast cancer, thus suggesting its involvement in the occurrence, invasion and distant metastasis of the tumor. In vitro studies have demonstrated that HOTAIR interacts with numerous chromatin-modifying enzymes to regulate target gene expression (10-12). HOTAIR acts as a bridge to coordinate the targeting of polycomb repressive complex 2 (PRC2), a histone H3 lysine 27 (H3K27)-specific methyltransferase complex, and lysine specific histone demethylase (LSD1)/(CoREST/REST complex) to chromatin for coupled histone H3K27 methylation and H3 lysine 4 demethylation, which is epigenetically involved in the silencing of genes in the HOXD cluster and several other target genes to promote tumor development and metastasis (13).

It has previously been confirmed that HOTAIR regulates metastasis of hepatocellular carcinoma, suggesting that it may be considered a useful target to reduce tumor recurrence (14). HOTAIR has the potential to predict tumor recurrence following liver transplantation, demonstrating its value as a prognostic indicator (14). The upregulation of HOTAIR is also associated with the malignant degree of colorectalcancer $(15,16)$, gastrointestinal stromal tumors (17), lung cancer (18), pancreatic cancer (19), nasopharyngeal carcinoma (20), laryngeal carcinoma (21) and ovarian cancer (22). In these cancers, HOTAIR is expressed at higher levels in the presence of lymph node involvement or organ metastasis, and higher levels correlate with a poorer prognosis and higher mortality. However, the mechanisms underlying the participation of HOTAIR in tumor occurrence, invasion and metastasis remain unclear.

The epithelial-mesenchymal transition (EMT) has been identified as one of the key mechanisms underlying ESCC tumor invasion and metastasis, and has been clinically associated with poor prognosis (23). EMT is characterized by a loss of epithelial characteristics and an acquisition of a mesenchymal state that reduces cell adhesion and enables ESCC tumor cells to dissociate from the epithelial tissue and migrate more effectively (24).

Notably, previous studies have reported that HOTAIR induces zinc finger protein SNAI1 (Snail), E-cadherin, matrix metalloproteinases (MMPs) and other EMT-related factors in breast (25), colorectal (16) and lung cancers (18). EMT-related factors are important in the development and metastasis of various types of cancer. In the present study, HOTAIR mRNA expression, and EMT-related mRNA and protein (Snail, $\beta$-catenin, E-cadherin) expression, was detected in ESCC and para-carcinoma tissues using reverse transcription-quantitative polymerase chain reaction (RT-qPCR) and western blot analysis. The correlation between these factors and the clinicopathological characteristics of patients with ESCC was also explored.

\section{Materials and methods}

Ethics. The present study was approved by the Ethics Committee of the Tumor Hospital of Xinjiang Medical University (Urumqi, China) and was performed in accordance with the Declaration of Helsinki of the World Medical Association. All patients provided written informed consent.
Clinicopathological data. A total of 96 ESCC specimens with matched para-carcinoma tissues, which were obtained during surgery from 2009 to 2014, were collected from the Tumor Hospital of Xinjiang Medical University (Urumqi, China). The samples were collected from 56 males and 40 females, with an average age of 60.7 years. According to the 2010 American Joint Committee on Cancer TNM stages (26), the 96 cases were classified as follows: 8 cases of well-differentiated ESCC (G1); 48 cases of moderately differentiated $\operatorname{ESCC}(\mathrm{G} 2)$; and 40 cases of poorly differentiated ESCC (G3). The TNM stages (26) of the 96 ESCC cases were as follows: 45 cases of stage I and II, 29 cases of stage III and 22 cases of stage IV. The tumors were located in the upper-middle section of the esophagus in 90 cases, and located in the lower section in 6 cases. There were 4 cases of $\mathrm{T} 1$ and 2, and 92 cases of $\mathrm{T} 3$ and 4, indicating the size and extent of the primary tumor. There were 52 cases with lymph node metastasis and 44 cases without lymph node metastasis, 22 cases with organ metastasis and 74 cases without organ metastasis. All patients had complete clinical data and had not received any pre-operative treatment.

$R T$-qPCR. Total RNA from homogenized cancerous and para-carcinoma specimens was extracted using TRIzol ${ }^{\circledR}$ reagent (Invitrogen; Thermo Fisher Scientific, Inc., Waltham, MA, USA) according to the manufacturer's protocol. cDNA was obtained by reverse transcribing total RNA using a TaqMan Reverse Transcription kit (Takara Bio, Inc., Dalian, China). The reaction system included $2 \mu 15 \mathrm{X}$ PrimeScript Buffer, $0.5 \mu \mathrm{l}$ PrimeScript RT Enzyme Mix I, $0.5 \mu \mathrm{l}$ oligo (dT) Primer $(50 \mu \mathrm{M}), 0.5 \mu 1$, Random 6 mers $(100 \mu \mathrm{M}), 500 \mathrm{ng}$ Total RNA and RNase free $\mathrm{dH}_{2} \mathrm{O}$ to reach a final volume of $10 \mu \mathrm{l}$. It was then reacted at $37^{\circ} \mathrm{C}$ for $15 \mathrm{~min}, 85^{\circ} \mathrm{C}$ for $5 \mathrm{sec}$, and $4^{\circ} \mathrm{C}$ for preservation. RT-qPCR analyses were conducted using the Power SYBR-Green kit (Takara Bio, Inc.), according to the manufacturer's protocol. All RT-qPCR assays were performed on an ABI 7500 Fast Real-Time PCR system (Applied Biosystems, Thermo Fisher Scientific, Inc.). The total volume of the reaction mixture was $20 \mu \mathrm{l}(2 \mu \mathrm{l}$ reverse transcriptase, $0.8 \mu \mathrm{l}$ each forward and reverse template RNA primers, $6.4 \mu 1$ sterilized diethylpyrocarbonate water, and $10 \mu \mathrm{l}$ SYBR Select Master mix). The initialization step (uracil-DNA glycosylation activation step) was set at $50^{\circ} \mathrm{C}$ for $2 \mathrm{~min}$, followed by the AmpliTaq DNA polymerase ultrapure activation step at $95^{\circ} \mathrm{C}$ for $2 \mathrm{~min}$. The denaturation temperature was $95^{\circ} \mathrm{C}$, held for $15 \mathrm{sec}$, and annealing of primers for E-cadherin, Snail, and $\beta$-catenin was carried out at $55^{\circ} \mathrm{C}$ for $15 \mathrm{sec}$. Extension was carried out at $72^{\circ} \mathrm{C}$ for $1 \mathrm{~min}$. The annealing/extension steps for HOTAIR were carried out at $60^{\circ} \mathrm{C}$ for $1 \mathrm{~min}$. The final three steps were run for 40 cycles. Expression levels of HOTAIR, Snail, E-cadherin, and $\beta$-catenin were normalized to those of $\beta$-actin.

The mRNA expression levels of HOTAIR and EMT-related factors were determined by RT-qPCR using the following primer sequences: HOTAIR forward, 5'-GCC TTTCCCTGCTACTTGTG-3', reverse, 5'GGCTGGACC TTTGCTTCTATG-3'; Snail forward, 5'-TGACCTGTCTGC AAATGCTC-3', reverse, 5'-CAGACCCTGGTTGCTTCA A-3'; E-cadherin forward, 5'-AGCGTGTGTGACTGTGAA GG-3', reverse, 5'-GCTGGCTCAAGTCAAAGTCC-3'; and $\beta$-catenin forward, 5'-CCCACTAATGTCCAGCGTTT-3' 
and reverse, 5'-TGTCAGTTCAGGGATTGCAC-3'. $\beta$-actin was used as an internal control, and the primer sequences were as follows: Forward, 5'-CATCATGAAGTGTGACGT GGA-3' and reverse, 5'-ACATCTGCTGGAAGGTGGAC-3'. All RT-qPCR assays were performed on an ABI 7500 Fast Real-Time PCR system (Applied Biosystems; Thermo Fisher Scientific, Inc.). HOTAIR, Snail, E-cadherin, and $\beta$-catenin values were normalized to those of $\beta$-actin, and their relative fold-changes in mRNA expression were calculated using the $2^{-\Delta \Delta C q}$ method (27).

Western blot analysis. All homogenized tissues were lysed using the mammalian protein extraction reagent radioimmunoprecipitation assay buffer (Beyotime Institute of Biotechnology, Haimen, China) supplemented with phenylmethylsulfonyl fluoride (Roche Molecular Diagnostics, Pleasanton, CA, USA). Extracted proteins $(\sim 30 \mu \mathrm{g})$ were separated by $8 \%$ SDS-PAGE, transferred to $0.45 \mu$ m polyvinylidene fluoride (PVDF) membranes (Merck Millipore, Darmstadt, Germany), and incubated with the indicated primary and secondary antibodies. The PVDF membrane was blocked with 1X TBST (Beijing Solarbio Science \& Technology Co., Ltd.) with 5\% milk for $2 \mathrm{~h}$, before being washed twice with TBST buffer. Primary antibodies $(1: 1,500)$ were incubated with the membrane at $4^{\circ} \mathrm{C}$ overnight. The PVDF membrane was washed 3 times for 10 min each, and incubated with secondary antibody $(1: 5,000)$ at room temperature for $1 \mathrm{~h}$. Following this, the membrane was washed for 3 times again with TBST.

Signals were detectedusing an enhanced chemiluminescence detection system (Bio-Rad Laboratories, Inc., Hercules, CA, USA). $\beta$-actin (cat. no. sc-47778) was used as an internal control. Rabbit-derived Snail (cat. no. sc-28199), E-cadherin (cat. no. sc-7870) and $\beta$-catenin primary antibodies (cat. no. sc-7199) were purchased from Santa Cruz Biotechnology, Inc. (Dallas, TX, USA). The secondary antibody, horseradish peroxidase-labeled goat anti-rabbit immunoglobulin $\mathrm{G}$, was purchased from Beijing Zhongshan Golden Bridge Biotechnology; OriGene Technologies, Inc. (cat. no. ZB-2301; Rockville, MD, USA).

Statistical analysis. All data were presented as M(P25, P75) and were analyzed using SPSS17.0 software (SPSS, Inc., Chicago, IL, USA). Rank-sum tests and Kruskal-Wallis tests were used to analyze clinicopathological parameter differences between groups. Spearman's rank correlation analysis was used to analyze the relationship between HOTAIR and EMT-related factors. $\mathrm{P}<0.05$ was considered to indicate a statistically significant difference.

\section{Results}

HOTAIR mRNA expression levels in ESCC and para-carcinoma tissues. The mRNA expression levels of HOTAIR were significantly higher in ESCC tissues compared within para-carcinoma tissues $(\mathrm{P}<0.0001$; Fig. 1A; Table I). HOTAIR mRNA expression levels in the groups with lymph node involvement or organ metastasis were significantly higher compared within the group without lymph node involvement or organ metastasis $(\mathrm{P}<0.0001$ and $\mathrm{P}=0.0003$, respectively; Table II). HOTAIR mRNA expression levels demonstrated a significantly increasing trend from well-differentiated cancer through moderately-differentiated cancer to poorly differentiated cancer, and a more advanced TNM stage was significantly rank correlated with increased HOTAIR mRNA expression levels $(\mathrm{P}<0.0001$; Table II). There was no significant correlation between HOTAIR mRNA expression levels and the tumor location, tumor invasion depth, or the age, ethnicity or gender of the patients (Table II).

$m R N A$ and protein expression levels of EMT-related factors (Snail, E-cadherin, $\beta$-catenin) in ESCC and para-carcinoma tissues. The mRNA expression levels of EMT-related factors are presented in Fig. 1B-D. The relative mRNA expression levels of Snail and $\beta$-catenin in ESCC were significantly higher compared with in para-carcinoma tissues $(\mathrm{P}<0.0001$ and $\mathrm{P}=0.0109$, respectively; Fig. $1 \mathrm{~B}$ and $\mathrm{C}$; Table I). In addition, Snail and $\beta$-catenin protein expression levels were significantly increased in ESCC compared with in para-carcinoma tissues $(\mathrm{P}<0.0001$ and $\mathrm{P}<0.0001$, respectively; Fig. 2; Table III). Conversely, E-cadherin mRNA expression level was significantly decreased in ESCC compared with para-carcinoma tissues $(\mathrm{P}<0.0001$; Fig. 1D; Table I), and the E-cadherin protein expression level was also significantly decreased in ESCC compared with para-carcinoma tissues ( $\mathrm{P}=0.0006$; Fig. 2; Table III).

The mRNA and protein expression levels of Snail in the groups with lymph node involvement or organ metastasis were significantly increased compared with the group without lymph node involvement or organ metastasis (mRNA, $\mathrm{P}<0.001$; protein, $\mathrm{P}=0.0005$; Table IV) or organ metastasis (mRNA, $\mathrm{P}<0.001$; protein, $\mathrm{P}=0.0035$; Table IV). Snail expression demonstrated an increasing trend from well-differentiated through moderately-differentiated to poorly differentiated cancer $\left(\mathrm{P}_{\mathrm{mRNA}}=0.0007, \mathrm{P}_{\text {protein }}<0.001\right.$; Table IV $)$, and a more advanced TNM stage was significantly correlated with increased Snail expression $\left(\mathrm{P}_{\mathrm{mRNA}}<0.0001, \mathrm{P}_{\text {protein }}<0.0001\right.$; Table IV) E-cadherin mRNA and protein expression levels were significantly decreased in the group with lymph node involvement (mRNA, $\mathrm{P}<0.001$; protein, $\mathrm{P}=0.0016$; Table IV) and organ metastasis (mRNA, $\mathrm{P}<0.001$; protein, $\mathrm{P}=0.0140$; Table IV) compared with the group without lymph node involvement or organ metastasis. The expression of E-cadherin demonstrated a significant decreasing trend from well-differentiated cancer through moderately-differentiated cancer to poorly differentiated cancer with significant rank correlation $\left(\mathrm{P}_{\mathrm{mRNA}}=0.0007\right.$, $\mathrm{P}_{\text {protein }}=0.0220$; Table IV). In addition, a more advanced TNM stage was significantly rank correlated with decreased E-cadherin expression $\left(\mathrm{P}_{\mathrm{mRNA}}=0.0002, \mathrm{P}_{\text {protein }}<0.0001\right.$; Table IV).

$\beta$-catenin mRNA and protein expression levels demonstrated a significantly increasing trend from well-differentiated cancer through moderately-differentiated cancer to poorly-differentiated cancer, and had a significant rank correlation $\left(\mathrm{P}_{\mathrm{mRNA}}=0.0019, \mathrm{P}_{\text {protein }}<0.0049\right.$; Table IV). A more advanced TNM stage was significantly rank correlated with increased $\beta$-catenin mRNA and protein expression $\left(\mathrm{P}_{\mathrm{mRNA}}=0.0306, \mathrm{P}_{\text {protein }}=0.0003\right.$; Table IV $) . \beta$-catenin protein expression was significantly increased in the groups with lymph node involvement $\left(\mathrm{P}_{\text {protein }}=0.0003\right.$; Table IV $)$ and organ metastasis $\left(\mathrm{P}_{\text {protein }}=0.0099\right.$; Table IV $)$, compared with the 
Table I. mRNA expression levels of HOTAIR and epithelial mesenchymal transition-related factors in ESCC and paired para-carcinoma tissues.

\begin{tabular}{lcccc}
\hline Tissue & HOTAIR & Snail & E-cadherin & $\beta$-catenin \\
\hline ESCC & $13.78(0.79,25.94)$ & $3.50(1.18,6.12)$ & $0.27(0.11,1.06)$ & $1.69(0.48,2.04)$ \\
Para-carcinoma & $1.00(1.00,1.00)$ & $1.00(1.00,1.00)$ & $1.00(1.00,1.00)$ & $1.00(1.00,1.00)$ \\
P-value & $<0.0001$ & $<0.0001$ & $<0.0001$ & 0.0109 \\
\hline
\end{tabular}

Data are expressed as M(P25, P75). HOTAIR, HOX transcript antisense RNA; ESCC, esophageal squamous cell carcinoma; Snail, zinc finger protein SNAI1.

Table II. Relationship between HOX transcript antisense RNA mRNA expression levels and clinicopathological factors of patients with esophageal squamous cell carcinoma.

\begin{tabular}{|c|c|c|c|}
\hline Characteristic & $\mathrm{N}$ & $2^{-\Delta \Delta C q}$ & P-value \\
\hline Gender & & & 0.8148 \\
\hline Male & 56 & $8.44(0.78,35.90)$ & \\
\hline Female & 40 & $13.78(7.04,21.84)$ & \\
\hline Age (years) & & & 0.1028 \\
\hline$>60$ & 60 & $12.14(0.81,19.89)$ & \\
\hline$\leq 60$ & 36 & $21.84(0.78,35.90)$ & \\
\hline Ethnicity & & $r_{k}=1.71$ & 0.4252 \\
\hline Wei & 32 & $14.00(1.34,20.20)$ & \\
\hline Han & 44 & $22.12(0.78,54.28)$ & \\
\hline $\mathrm{Ha}$ & 20 & $12.14(7.04,25.42)$ & \\
\hline T stage & & & 0.0599 \\
\hline $\mathrm{T} 1+\mathrm{T} 2$ & 4 & $25.28(24.28,54.28)$ & \\
\hline $\mathrm{T} 3+\mathrm{T} 4$ & 92 & $12.86(0.77,21.91)$ & \\
\hline $\mathrm{N}$ stage & & & $<0.0001$ \\
\hline Yes & 52 & $21.84(14.59,54.28)$ & \\
\hline No & 44 & $0.81(0.71,12.14)$ & \\
\hline M stage & & & 0.0003 \\
\hline Yes & 22 & $22.12(19.89,54.28)$ & \\
\hline No & 74 & $1.95(0.75,14.94)$ & \\
\hline Tumor location & & & 0.6615 \\
\hline Upper-mid & 90 & $13.57(0.81,22.12)$ & \\
\hline Under & 6 & $19.89(0.78,27.22)$ & \\
\hline G stage & & $\mathrm{r}_{\mathrm{k}}=8.612$ & 0.0135 \\
\hline G1 & 8 & $0.81(0.78,7.04)$ & \\
\hline $\mathrm{G} 2$ & 48 & $13.57(0.74,21.84)$ & \\
\hline G3 & 40 & $19.89(1.95,35.90)$ & \\
\hline TNM stage & & $\mathrm{r}_{\mathrm{k}}=38.79$ & $<0.0001$ \\
\hline $\mathrm{I}+\mathrm{II}$ & 45 & $0.80(0.71,1.95)$ & \\
\hline III & 29 & $14.25(7.04,20.20)$ & \\
\hline IV & 22 & $21.98(15.47,47.52)$ & \\
\hline
\end{tabular}

Data are expressed as $\mathrm{M}(\mathrm{P} 25, \mathrm{P} 75)$.

group with no lymph node or organ involvement. However, there was no significant correlation between $\beta$-catenin mRNA expression and lymph node or organ metastasis in the 96 esophageal cancer tissues ( $\mathrm{P}>0.05$; Table IV) There was no significant correlation between Snail, E-cadherin, or $\beta$-catenin expression and tumor location, invasion depth, or the age, ethnicity or gender of patients (Table IV).

Correlation between the expression levels of HOTAI RmRNA and EMT-related factors in ESCC. In the 96 ESCC tissues, HOTAIR mRNA expression levels were positively correlated with Snail and $\beta$-catenin mRNA expression levels $\left(r_{s}=0.4173\right.$ and 0.3049 , respectively, $\mathrm{P}<0.0001$ and $\mathrm{P}=0.0025$, respectively; Fig. 3). HOTAIR and E-cadherin mRNA expression levels were negatively correlated $\left(r_{\mathrm{s}}=-0.3270, \mathrm{P}=0.0011\right.$; Fig. 3 ).

HOTAIR expression was subsequently divided into a high level group and low level group, according to its mean expression level (17.58). In the HOTAIR high expression group, Snail protein expression was significantly higher compared with the low expression group ( $\mathrm{P}=0.0008$; Fig. 4A; Table V), whereas E-cadherin protein expression levels were significantly lower in the HOTAIR high expression group compared with the HOTAIR low expression group ( $\mathrm{P}=0.0381$; Fig. 4B; Table V). There was no relationship between HOTAIR mRNA expression levels and $\beta$-catenin protein expression levels ( $\mathrm{P}>0.05$; Fig. 4C; Table V).

\section{Discussion}

Cancer has traditionally been regarded as a genetic disease; however, but previous research has revealed that cancer development and progression are also associated with epigenetic abnormalities (28). Genetic continuity requires epigenetic regulation, including DNA methylation, histone deacetylation, chromatin remodeling, gene imprinting and noncoding RNA (ncRNA) regulation $(29,30)$. MicroRNAs and lncRNAs >200 nucleotides in length serve as the primary regulatory ncRNAs. Although microRNAs have been comprehensively studied in several types ofcancer, they have also been identified for potential use in esophageal cancer, and for early clinical diagnosis, prognosis, and gene therapy (31). Emerging evidence has indicated that lncRNAs possess more complicated and extensive regulatory functions than microRNAs in cancer development and progression (32-36)

HOTAIR, which is one of the few well-documented lncRNAs, is highly expressed in breast, hepatic, pancreatic, lung, and colorectal cancers. Increased HOTAIR 
A

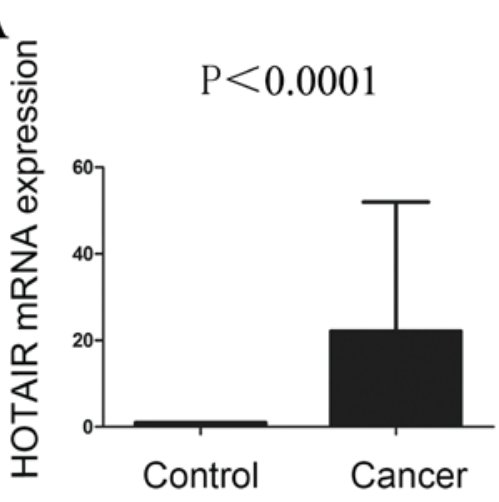

C

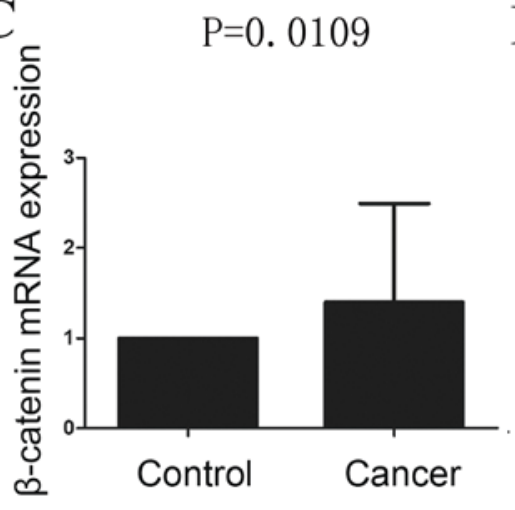

B

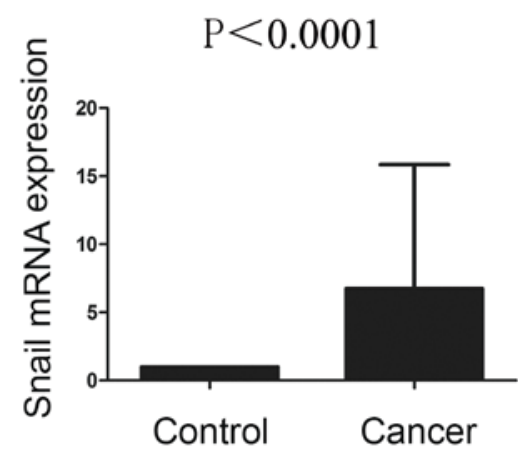

D $\quad \mathrm{P}<0.0001$

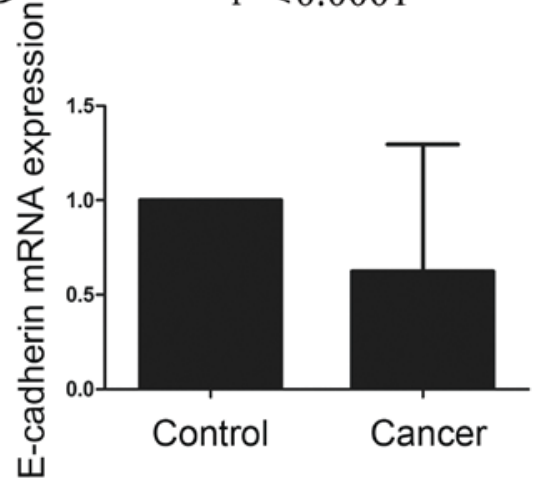

Figure 1. mRNA expression levels of (A) HOTAIR and the following epithelial mesenchymal transition-related factors: (B) Snail, (C) $\beta$-catenin and (D) E-cadherin in esophageal squamous cell carcinoma and paired para-carcinoma tissues. HOTAIR, HOX transcript antisense RNA; Snail, zinc finger protein SNAI1.

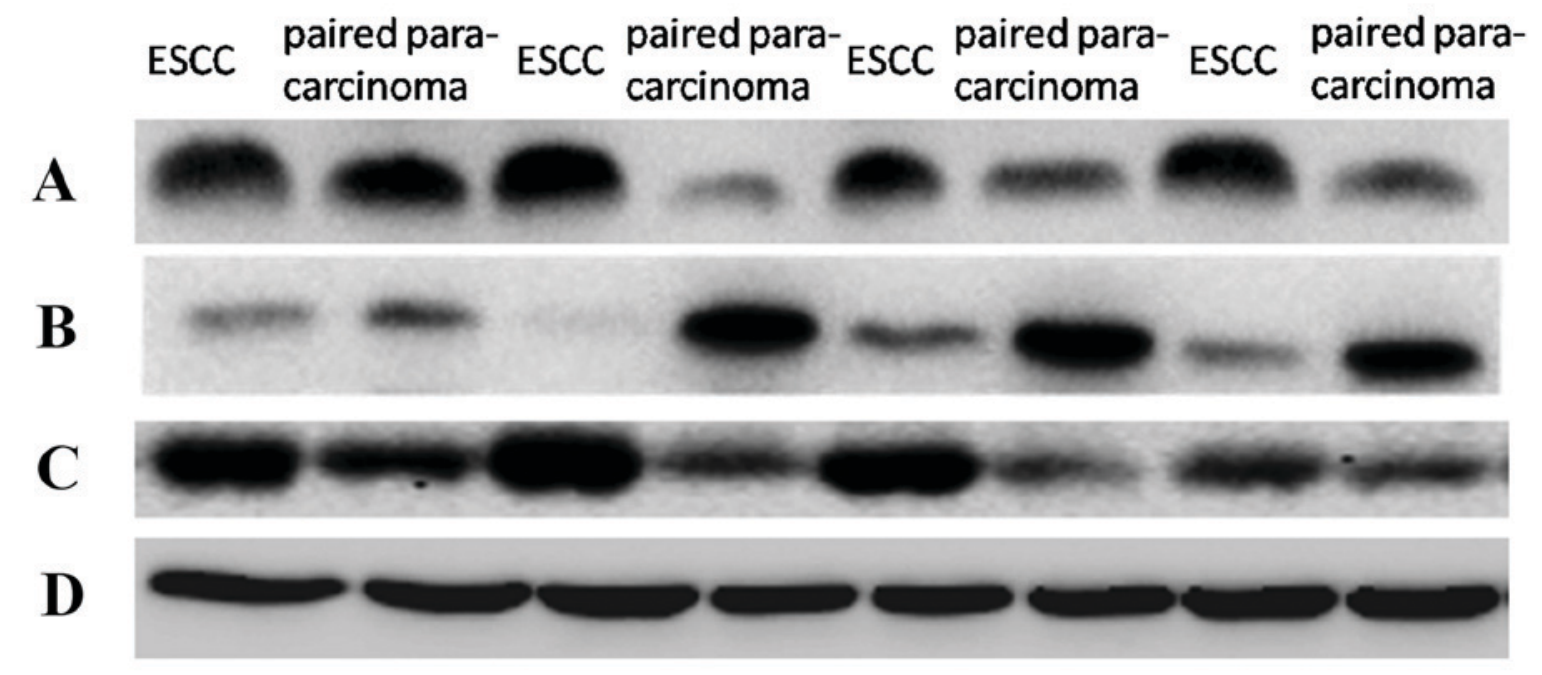

Figure 2. Protein expression levels of the following epithelial mesenchymal transition-related factors: (A) zinc finger protein SNAI1, (B) E-cadherin and (C) $\beta$-catenin in esophageal squamous cell carcinoma and paired para-carcinoma tissues. (D) $\beta$-actin was used as a control.

expression is correlated with enhanced cancer metastasis. Conversely, HOTAIR knockdown may inhibit cell invasion and proliferation, alter progression of the cell cycle, induce apoptosis, and increase sensitivity to radiochemotherapy, indicating that HOTAIR is involved in the modulation of cancer progression $(9,14,15,19,25,37,38)$. In the present study, HOTAIR mRNA expression levels were investigated in 96 ESCC and para-carcinoma tissues, and HOTAIR expression levels were significantly higher in ESCC compared within para-carcinoma tissues. HOTAIR expression levels 
Table III. Protein expression levels of epithelial mesenchymal transition-related factors in ESCC and paired para-carcinoma tissues.

\begin{tabular}{lccr}
\hline Tissue & Snail & E-cadherin & $\beta$-catenin \\
\hline ESCC & $1.43(1.04,2.09)$ & $0.20(0.04,0.47)$ & $1.40(1.02,1.89)$ \\
Para-carcinoma & $0.76(0.40,1.19)$ & $0.49(0.22,0.90)$ & $0.73(0.32,1.09)$ \\
P-value & $<0.0001$ & 0.0006 & $<0.0001$ \\
\hline
\end{tabular}

Data are expressed as M(P25, P75). ESCC, esophageal squamous cell carcinoma; Snail, zinc finger protein SNAI1.
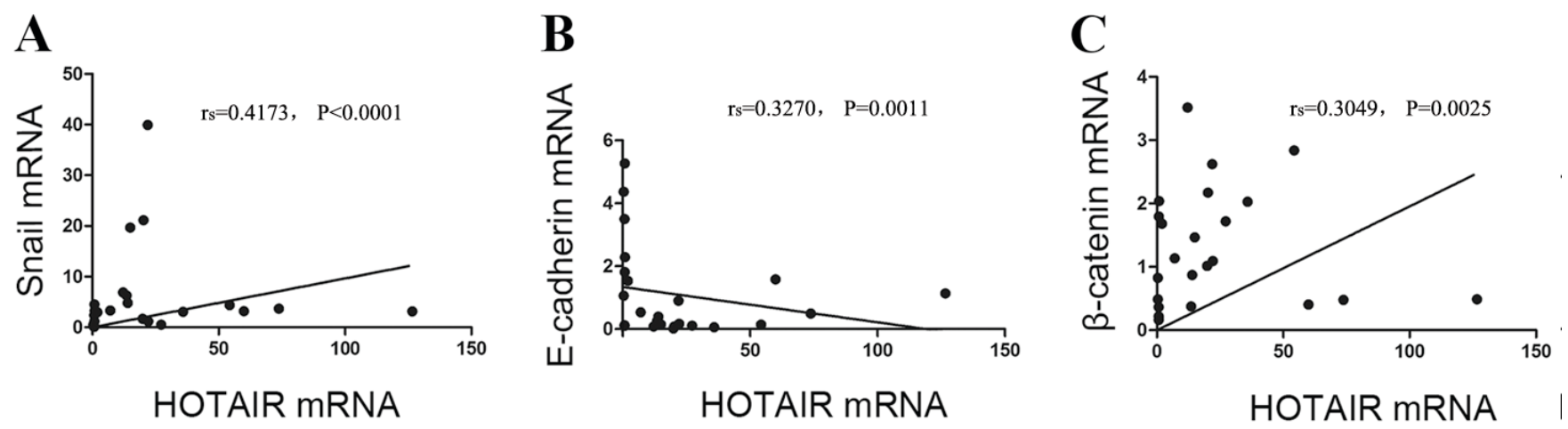

Figure 3. Correlations between mRNA expression levels of HOTAIR and the following epithelial mesenchymal transition-related factors: (A) Snail, (B) E-cadherin and (C) $\beta$-catenin. HOTAIR, HOX transcript antisense RNA; Snail, zinc finger protein SNAI1.

in the groups with lymph node or organ metastasis were significantly higher than in the group without metastasis. HOTAIR also demonstrated a significant increasing trend from well-differentiated cancer through moderately-differentiated cancer to poorly differentiated cancer, and the more advanced TNM stage was also significantly rank correlated with increased HOTAIR expression. Based on these results, upregulated HOTAIR mRNA expression appears to be heterogeneous among patients and is associated with various clinicopathological factors, including lymph node/organ metastasis, cancer differentiation and TNM stage. HOTAIR may participate in ESCC occurrence, differentiation and metastasis, and it may be a useful early diagnostic and prognostic marker.

EMT is involved in cancer development and metastasis, and this process is characterized by the loss of epithelial markers, including E-cadherin, and the gain of mesenchymal markers, including Snail and $\beta$-catenin. $\beta$-catenin is also a vital component of the Wnt signaling pathway.

Snail, which is a critical mesenchymal transcription factor, is highly expressed and closely correlated with poor tumor differentiation, metastasis, radiochemotherapy resistance, and short survival in lung (39), breast (40) and colon tumors (41). The injection of Snail into a pancreatic tumor mouse model significantly promoted metastasis in vivo (42). Inhibition of Snail expression also reduces the metastatic ability of ovarian carcinoma cells in vitro (43). Snail expression demonstrated a gradual increasing trend from well-differentiated cancer through moderated-differentiated to poorly-differentiated cancer, and a more advanced TNM stage was associated with increased Snail expression with a significant rank correlation, indicating that Snail may be involved in ESCC incidence, development and lymph node/organ metastasis. Therefore, Snail may also be considered a useful prognostic and predictive indicator for ESCC.

E-cadherin, which is expressed in epithelial cells, is thought to be a metastatic suppressor during tumor progression. E-cadherin mediates homotypic cell adhesion and maintains normal morphology, epithelial cell polarity, and tissue structural integrity by binding to cytosolic $\beta$-catenin, which is required for EMT, to form the E-cadherin/ $\beta$-catenin complex. The destruction of the E-cadherin/ $\beta$-catenin complex is closely correlated with the recurrence and metastasis of colon $(44,45)$, lung (46) and bladder cancers (47).

If the structure or function of $\beta$-catenin is abnormal, E-cadherin expression is lost, or the E-cadherin/ $\beta$-catenin complex is broken, tumor cells may become metastatic through reduced intracellular adherence and stimulated cell proliferation. This is often observed in breast, lung, gastrointestinal and other cancers (48-51). Zhao et al (52) demonstrated that the loss of E-cadherin and nuclear accumulation of $\beta$-catenin were correlated with poor prognosis for patients with head and neck squamous cell carcinoma.

The present study demonstrated that the E-cadherin mRNA and protein expression levels were significantly lower in ESCC compared with para-carcinoma tissues, whereas $\beta$-catenin mRNA and protein expression levels were significantly higher in ESCC compared with para-carcinoma tissues. Combined with previous reports, this indicates that E-cadherin and $\beta$-catenin are important to tumor development and metastasis. The present investigation indicated that E-cadherin and $\beta$-catenin may participate in the incidence, differentiation, 


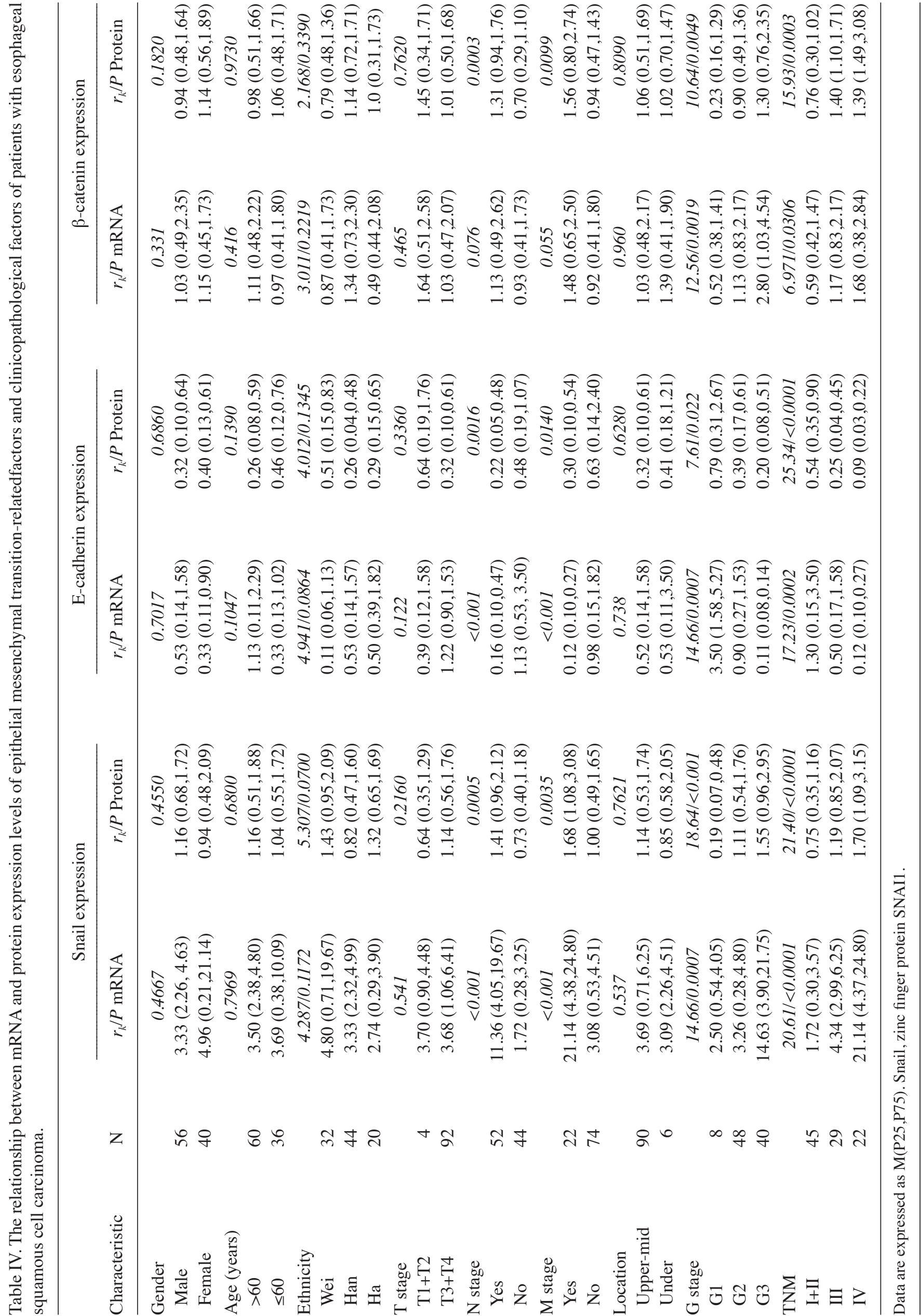


Table V. Correlations between HOTAIR mRNA expression levels and epithelial mesenchymal transition-related protein levels in esophageal squamous cell carcinoma.

\begin{tabular}{lccc}
\hline Group & Snail & E-cadherin & $\beta$-catenin \\
\hline HOTAIR high expression & $1.68(1.13,3.22)$ & $0.09(0.08,0.23)$ & $1.67(1.02,3.22)$ \\
HOTAIR low expression & $1.14(0.59,1.68)$ & $0.20(0.08,0.45)$ & $1.17(0.94,1.69)$ \\
P-value & 0.0008 & 0.0381 & 0.0939 \\
\hline
\end{tabular}

Data are expressed as M(P25, P75). HOTAIR, HOX transcript antisense RNA; Snail, zinc finger protein SNAI1.
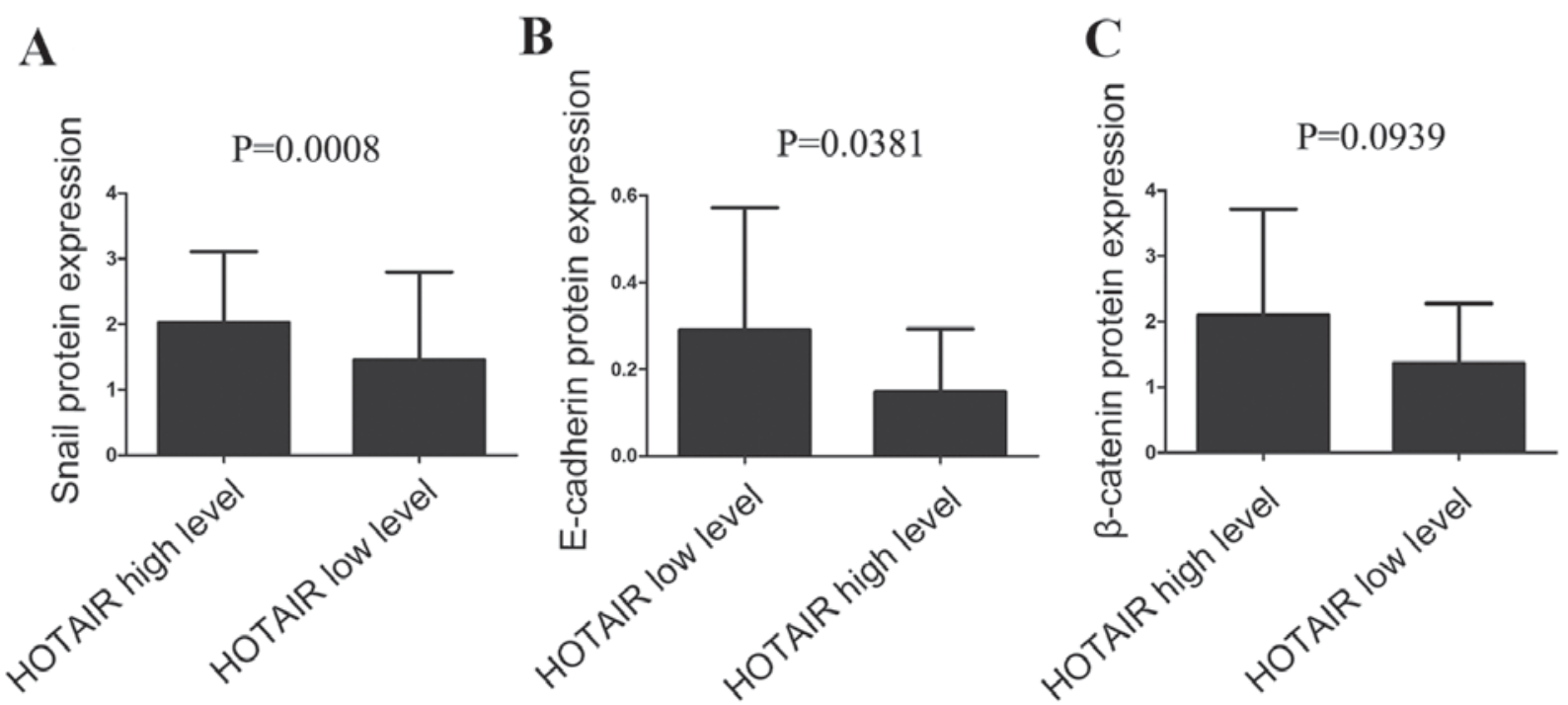

Figure 4. Correlations between HOTAIR mRNA expression levels and protein expression levels of the following epithelial mesenchymal transition-related proteins: (A) Snail, (B) E-cadherin and (C) $\beta$-catenin. HOTAIR, HOX transcript antisense RNA; Snail, zinc finger protein SNAI1.

invasion and metastasis of ESCC. These factors may therefore be useful for the early diagnosis and prognosis of ESCC.

Ge et al (53) revealed that high expression of HOTAIR activates the Wnt pathway by inhibiting Wnt inhibitory factor 1 expression, which leads to the accumulation of cytosolic $\beta$-catenin. This translocates to the nucleus to promote the expression of Snail, MMP13A, and other EMT-related factors. Although direct evidence is lacking, the involvement of HOTAIR in the regulation of EMT has been hypothesized. In addition to previous data demonstrating that HOTAIR affects $\beta$-catenin (53), other investigations have demonstrated that HOTAIR induces the expression of Snail $(19,25)$. Kogo et al $(15)$ used gene set enrichment analysis and demonstrated that HOTAIR overexpression in colorectal cancer maybe associated with the multipotent differentiation of colorectal cancer cells. Gene pathway analysis also indicated that HOTAIR-regulated gene sets included E-cadherin, which was lost in tissues with elevated HOTAIR expression. Xu et al (54) demonstrated that HOTAIR knockdown reversed EMT progression, leading to the upregulation of E-cadherin and the downregulation of $\mathrm{N}$-cadherin, the marker of the mesenchymal phenotype. Gastric cancer invasiveness, suppressed by HOTAIR knockdown, was also restored by exogenous Snail.

However, the relationship between HOTAIR and EMT-related factors in ESCC tissues remains unclear. The present study demonstrated that HOTAIR expression levels were positively correlated with Snail and $\beta$-catenin protein expression levels, whereas it was negatively correlated with E-cadherin protein expression levels.

Combined with these other results, HOTAIR appears to participate in tumor invasion and metastasis by directly or indirectly affecting the expression of EMT-related factors. Therefore, HOTAIR expression may be used as a specific indicator of tumor metastasis and prognosis and assist in therapeutic planning.

In conclusion, HOTAIR, together with EMT-related factors, may be a specific indicator for the occurrence, metastasis and prognosis of ESCC. The results of the present study supported the use of HOTAIR as a potential novel tumor molecular marker for use in future therapies. However, there are some limitations to the present study, including a small sample size. The specific mechanisms underlying how HOTAIR regulates EMT-related factors in ESCC require further investigation in future studies.

\section{Acknowledgements}

The present study was supported by the Natural Science Foundation of Xinjiang Uygur Autonomous Region (grant no. 2015211C115). 


\section{References}

1. Pakzad R, Mohammadian-Hafshejani A, Khosravi B, Soltani S, Pakzad I, Mohammadian M, Salehiniya H and Momenimovahed Z: The incidence and mortality of esophageal cancer and their relationship to development in Asia. Ann Transl Med 4: 29, 2016

2. Lin Y, Totsuka Y, He Y, Kikuchi S, Qiao Y, Ueda J, Wei W, Inoue $\mathrm{M}$ and Tanaka $\mathrm{H}$ : Epidemiology of esophageal cancer in Japan and China. J Epidemiol 23: 233-242, 2013.

3. Enzinger PC and Mayer RJ: Esophageal cancer. N Engl J Med 349: 2241-2252, 2003

4. Tepper JE: Is radiation therapy needed in the treatment of gastroesophageal junction adenocarcinoma? Gastrointest Cancer Res 2 (4 Suppl): S2-S5, 2008.

5. Linkous AG and Yazlovitskaya EM: Novel radiosensitizing anticancer therapeutics. Anticancer Res 32: 2487-2499, 2012

6. Kotake Y, Nakagawa T,Kitagawa K, Suzuki S, Liu N, Kitagawa M and Xiong Y: Long non-coding RNA ANRIL is required for the PRC2 recruitment to and silencing of p15(INK4B) tumor suppressor gene. Oncogene 30: 1956-1962, 2011.

7. Wu HA and Bernstein E: Partners in imprinting: Noncoding RNA and polycomb group proteins. Dev Cell 15: 637-638, 2008.

8. Khalil AM, Guttman M, Huarte M, Garber M, Raj A Rivea Morales D, Thomas K, Presser A, Bernstein BE, van Oudenaarden A, et al: Many human large intergenic noncoding RNAs associate with chromatin-modifying complexes and affect gene expression. Proc Natl Acad Sci USA 106: $11667-11672,2009$.

9. Rinn JL, Kertesz M, Wang JK, Squazzo SL, Xu X, Brugmann SA, Goodnough LH, Helms JA, Farnham PJ, Segal E and Chang HY: Functional demarcation of active and silent chromatin domains in human HOX loci by noncoding RNAs. Cell 129: 1311-1323, 2007.

10. Chu C, Qu K, Zhong FL, Artandi SE and Chang HY: Genomic maps of long noncoding RNA occupancy reveal principles of RNA-chromatin interactions. Mol Cell 44: 667-678, 2011.

11. Kogo R, Shimamura T, Mimori K, Kawahara K, Imoto S, Sudo T, Tanaka F, Shibata K, Suzuki A, Komune S, et al: Long noncoding RNA HOTAIR regulates polycomb-dependent chromatin modification and is associated with poor prognosis in colorectal cancers. Cancer Res 71: 6320-6326, 2011.

12. Bhan A and Mandal SS: LncRNA HOTAIR: A master regulator of chromatin dynamics and cancer. Biochim Biophys Acta 1856: 151-164, 2015

13. Tsai MC, Manor O, Wan Y, Mosammaparast N, Wang JK, Lan F, Shi Y, Segal E and Chang HY: Long noncoding RNA as modular scaffold of histone modification complexes. Science 329: 689-693, 2010

14. Yang Z, Zhou L, Wu LM, Lai MC, Xie HY, Zhang F and Zheng SS: Overexpression of long non-coding RNA HOTAIR predicts tumor recurrence in hepatocellular carcinoma patients following liver transplantation. Ann Surg Oncol 18: 1243-1250, 2011.

15. Kogo R, Shimamura T, Mimori K, Kawahara K, Imoto S, Sudo T, Tanaka F, Shibata K, Suzuki A, Komune S, et al: Long noncoding RNA HOTAIR regulates polycomb-dependent chromatin modification and is associated with poor prognosis in colorectal cancers. Cancer Res 71: 6320-6326, 2011.

16. Wu ZH, Wang XL, Tang HM, Jiang T, Chen J, Lu S, Qiu GQ, Peng ZH and Yan DW: Long non-coding RNA HOTAIR is a powerful predictor of metastasis and poor prognosis and is associated with epithelial-mesenchymal transition in colon cancer. Oncol Rep 32: 395-402, 2014.

17. Niinuma T, Suzuki H, Nojima M, Nosho K, Yamamoto $H$ Takamaru H, Yamamoto E, Maruyama R, Nobuoka T, Miyazaki Y, et al: Upregulation of miR-196a and HOTAIR drive malignant character in gastrointestinal stromal tumors. Cancer Res 72: 1126-1136, 2012.

18. Liu XH, Liu ZL, Sun M, Liu J, Wang ZX and De W: The long non-coding RNA HOTAIR indicates a poor prognosis and promotes metastasis in non-small cell lung cancer. BMC Cancer 13: 464, 2013

19. Kim K, Jutooru I, Chadalapaka G, Johnson G, Frank J, Burghardt R, Kim S and Safe S: HOTAIR is a negative prognostic factor and exhibits pro-oncogenic activity in pancreatic cancer. Oncogene 32: 1616-1625, 2013.

20. Nie Y, Liu X, Qu S, Song E, Zou H and Gong CL: Non-coding RNA HOTAIR is an independent prognostic marker for nasopharyngeal carcinoma progression and survival. Cancer Sci 104 458-464, 2013
21. Li D, Feng J, Wu T, Wang Y, Sun Y, Ren J and Liu M: Long intergenic noncoding RNA HOTAIR is overexpressed and regulates PTEN methylation in laryngeal squamous cell carcinoma. Am J Pathol 182: 64-70, 2013

22. Cui L, Xie XY, Wang H, Chen XL, Liu SL and Hu LN Expression of long non-coding RNA HOTAIR mRNA in ovarian cancer. Sichuan Da Xue Xue Bao Yi Xue Ban 44: 57-59, 2013 (In Chinese).

23. Sung CO, Park CK and Kim SH: Classification of epithelial-mesenchymal transition phenotypes in esophageal squamous cell carcinoma is strongly associated with patient prognosis. Mod Pathol 24: 1060-1068, 2011

24. Iwatsuki M, Mimori K, Yokobori T, Ishi H, Beppu T, Nakamori S, Baba $\mathrm{H}$ and Mori M: Epithelialmesenchymal transition in cancer development and its clinical significance. Cancer Sci 101: 293-299, 2010.

25. Gupta RA, Shah N, Wang KC, Kim J, Horlings HM, Wong DJ, Tsai MC, Hung T, Argani P, Rinn JL, et al: Long non-coding RNA HOTAIR reprograms chromatin state to promote cancer metastasis. Nature 464: 1071-1076, 2010.

26. Chen LQ: Understanding and appraisal of the new TNM classification for esophageal cancer in the AJCC Cancer Staging Manual (7th edition). Zhonghua Zhong Liu Za Zhi 32: 237-240, 2010.

27. Livak KJ and Schmittgen TD: Analysis of relative gene expression data using real-time quantitative PCR and the 2(-Delta Delta C(T)) Method. Methods 25: 402-408, 2001

28. Sharma S, Kelly TK and Jones PA: Epigenetics in cancer. Carcinogemesis 31: 27-36, 2010.

29. Banerjee HN and Verma M: Epigenetic mechanisms in cancer Biomark Med 3: 397-410, 2009.

30. Esteller M: Epigenetics in cancer. N Engl J Med 358: 1148-1159, 2008.

31. Li SQ, Wang HM and Cao XF: Potential clinical insights into microRNAs and their target genes in esophageal carcinoma. Biomarkers 16: 629-636, 2011.

32. Lin R, Maeda S, Liu C, Karin M and Edgington TS: A large noncoding RNA is a marker for murine hepatocellular carcinomas and a spectrum of human carcinomas. Oncogene 26: 851-858, 2007.

33. Matouk IJ, DeGroot N, Mezan S, Ayesh S, Abu-lail R, Hochberg A and Galun E: The H19 non-coding RNA is essential for human tumor growth. PLoS One 2: e845, 2007.

34. Pasmant E, Sabbagh A, Masliah-Planchon J, Ortonne N, Laurendeau I, Melin L, Ferkal S, Hernandez L, Leroy K, Valeyrie-Allanore L, et al: Role of noncoding RNA ANRIL in genesis of plexiform neurofibromas in neurofibromatosis type 1 . J Natl Cancer Inst 103: 1713-1722, 2011.

35. Silva JM, Boczek NJ, Berres MW, Ma X and Smith DI: LSINCT5 is overexpressed in breast and ovarian cancer and affects cellular proliferation. RNA Biol 8: 496-505, 2011.

36. Srikantan V, Zou Z, Petrovics G, Xu L, Augustus M, Davis L, Livezey JR, Connell T, Sesterhenn IA, Yoshino K, et al: PCGEM1, a prostate-specific gene, is overexpressed in prostate cancer. Proc Natl Acad Sci USA 97: 12216-12221, 2000

37. Kurrey NK, Jalgaonkar SP, Joglekar AV, Ghanate AD, Chaskar PD, Doiphode RY and Bapat SA: Snail and slug mediate radioresistance and chemoresistance by antagonizing p53-mediated apoptosis and acquiring a stem-like phenotype in ovarian cancer cells. Stem Cells 27: 2059-2068, 2009.

38. Wang Y, Shi J, Chai K, Ying X and Zhou BP: The role of snail in EMT and tumorigenesis. Curr Cancer Drug Targets 13: 963-972, 2013.

39. Galván JA, González MV, Crespo G, Folgueras MV and Astudillo A: Snail nuclear expression parallels higher malignancy potential in neuroendocrine lung tumors. Lung Cancer 69: 289-295, 2010.

40. Olmeda D, Moreno-Bueno G, Flores JM, Fabra A, Portillo F and Cano A: SNAI1 is required for tumor growth and lymph node metastasis of human breast carcinoma MDA-MB-231 cells. Cancer Res 67: 11721-11731, 2007.

41. Francí C, Gallén M, Alameda F, Baró T, Iglesias M, Virtanen I and García de Herreros A: Snaill protein in the stroma as a new putative prognosis marker for colon tumours. PLoS One 4: e5595, 2009.

42. Nishioka R, Itoh S, Gui T, Gai Z, Oikawa K, Kawai M, Tani M, Yamaue $\mathrm{H}$ and Muragaki Y: SNAIL induces epithelial-to-mesenchymal transition in a human pancreatic cancer cell line (BxPC3) and promotes distant metastasis and invasiveness in vivo. Exp Mol Pathol 89: 149-157, 2010 
43. Jin H, Yu Y, Zhang T, Zhou X, Zhou J, Jia L, Wu Y, Zhou BP and Feng Y: Snail is critical for tumor growth and metastasis of ovarian carcinoma. Int J Cancer 126: 2102-2111, 2010.

44. Aamodt R, Bondi J, Andersen SN, Bakka A, Bukholm G and Bukholm IR: The prognostic impact of protein expression of E-cadherin-catenin complexes differs between rectal and colon carcinoma. Gastroenterol Res Pract 2010: 616023, 2010.

45. Kang H, Min BS, Lee KY, Kim NK, Kim SN, Choi J and Kim H: Loss of E-cadherin and MUC2 expressions correlated with poor survival in patients with stages II and III colorectal carcinoma. Ann Surg Oncol 18: 711-719, 2011.

46. Chelidonis G, Kavantzas N, Patsouris E, Pagaki E, Agrogiannis G and Athanasiadou P: DNA ploidy, E-cadherin, beta-catenin expression and their clinicopathologic significance in imprints of non-small cell lung cancer. Anal Quant Cytol Histol 31: 332-339, 2009.

47. Baumgart E, Cohen MS, Silva Neto B, Jacobs MA, Wotkowicz C, Rieger-Christ KM, Biolo A, Zeheb R, Loda M, Libertino JA and Summerhayes IC: Identification and prognostic significance of an epithelial-mesenchymal transition expression profile in human bladder tumors. Clin Cancer Res 13: 1685-1694, 2007.

48. Christofori $\mathrm{G}$ and Semb H: The role of the cell-adhesion molecule E-cadherin as a tumour suppressor gene. Trends Biochem Sci 24: 73-76, 1999.

49. Adhikary A, Chakraborty S, Mazumdar M, Ghosh S, Mukherjee S, Manna A, Mohanty S, Nakka KK, Joshi S, De A, et al: Inhibition of epithelial to mesenchymal transition by E-cadherin up-regulation via repression of slug transcription and inhibition of E-cadherin degradation: Dual role of scaffold/matrix attachment region-binding protein 1 (SMAR1) in breast cancer cells. J Biol Chem 289: 25431-25444, 2014
50. Beck TN, Chikwem AJ, Solanki NR and Golemis EA: Bioinformatic approaches to augment study of epithelial-to-mesenchymal transition (EMT) in lung cancer. Physiol Genomics 2014: 699-724, 2014.

51. Zheng H, Li W, Wang Y, Xie T, Cai Y, Wang Z and Jiang B: miR-23a inhibits E-cadherin expression and is regulated by AP-1 and NFAT4 complex during Fas-induced EMT in gastrointestinal cancer. Carcinogenesis 35: 173-183, 2014.

52. Zhao Z, Ge J, Sun Y, Tian L, Lu J, Liu M and Zhao Y: Is E-cadherin immunoexpression a prognostic factor for head and neck squamous cell carcinoma (HNSCC)? A systematic review and meta-analysis. Oral Oncol 48: 761-767, 2012.

53. Ge XS, Ma HJ, Zheng XH, Ruan HL, Liao XY, Xue WQ, Chen YB, Zhang Y and Jia WH: HOTAIR, A prognostic factor in esophageal squamous cell carcinoma, inhibits WIF-1 expression and activates Wnt pathway. Cancer Sci 104: 1675-1682, 2013.

54. Xu ZY, Yu QM, Du YA, Yang LT, Dong RZ, Huang L, Yu PF and Cheng XD: Knockdown of long non-coding RNA HOTAIR suppresses tumor invasion and reverses epithelial- mesenchymal transition in gastric cancer. Int J Biol Sci 9: 587-597, 2013. 